\title{
Devenir en Padres: Un análisis de las prácticas de resistencia de la organización H.I.J.O.S Bogotá ${ }^{1}$
}

\author{
G. Angélica Vásquez Zárate \\ Master Cultura de la Paz \\ angelica.vazquezzarate@alum.uca.es
}

\section{Reseña}

El artículo académico denominado Devenir en padres: un análisis de las prácticas de resistencia de la organización HIJOS Bogotá, fue el resultado de tres años de investigación en el marco de la Maestría en Investigación en Problemas Sociales Contemporáneos del Instituto de Estudios Contemporáneos de la Universidad Central. Fue publicado en el Vol. 40 (1) del 2017 de la Revista de Sociología de la Universidad Nacional de Colombia, denominado: Memorias del presente y del futuro: ¿cómo, para quién, para qué?. Está disponible en distintas bases de datos de alto nivel de consulta.

El articulo analiza las prácticas que H.I.J.O.S. "por la identidad y la justicia, contra el olvido y el silencio" desarrolla para no olvidar y mantener vigente el legado de sus padres. En el primer apartado se caracteriza a la organización como generacional y resiliente, integrada por hijos/as que perdieron a sus padres a causa de la violencia sociopolítica que en Colombia se libró al finalizar los años ochenta. En esta descripción se aclara que sus padres fueron asesinados por agentes del Estado, luego de haber firmado el respectivo acuerdo de paz con el gobierno nacional, hecho que no fue reconocido durante 30 años. En este mismo apartado se describe la metodología usada y el corpus documental seleccionado en el desarrollo del estudio.

En el segundo apartado se hace un análisis de la subjetividad política de la organización, esta se hace a través de la descripción de las prácticas que desarrolla, para exigir el esclarecimiento de la verdad de los hechos de violencia en los que perdieron a sus padres. Se argumenta que la subjetividad política emerge del relato de vida de los padres, pues tiene la potencia de conectar la historia familiar (campo de lo privado) con la historia oficial (campo de lo público). En este sentido, se comprende la memoria desde una perspectiva transformadora como fuente y potencia de cambio, dado que se fundamenta en

${ }^{1}$ Recibido: 30/03/2018 Evaluado: 13/04/2018 Aceptado: 11/05/2018 
una serie de prácticas intencionadas que a través del recuerdo personal, pretenden sacar del olvido hechos de la violencia política del pasado para otorgarle un sentido diferente que le posibilite a los sujetos intervenir en el presente y devenir en el futuro.

Los hechos sobre los que hijos/as hace memoria -selectivamente escogidos- genera unos marcos de interpretación común de los hechos del pasado, sobre los que se sustenta la identidad generacional de la organización.

En esta misma sección se menciona como la visibilidad de la organización se soporta en los relatos de los hijos/as y en el simbolismo usado en el desarrollo de las acciones de memoria. Este simbolismo se configura alrededor de las siguientes relaciones: imagenpresencia (cuerpo), discursos-representación (lo dicho) y experiencia-acción (lugar). Los anteriores vínculos evocan unos efectos alegóricos que llevan al espectador a considerar que la "memoria es viva" al momento de: 1) presentarse una similitud corporal de los hijos/as con los padres; 2) identificar en los discursos reivindicativos de los hijos/as los ideales políticos de los padres y 3 ) al desarrollar las acciones en lugares que guardan una historia con la memoria a dignificar.

En el tercer apartado se analiza cómo mantener vigente el legado de los padres lleva a los hijos/as a actuar desde las instituciones del Estado, movimiento social y/o en escenarios de representación política y cómo esta actuación conlleva a que existan diferencias entren los hijos/as alrededor del "deber ser" en el actuar de la organización.

Entre los escenarios que fueron analizados estuvo el de negociación de Paz entre el Gobierno Nacional con las Fuerzas Armadas Revolucionarias de Colombia (FARC). A este, algunos de los hijos/as fueron invitados para que aportasen propuestas en el punto de reparación a las víctimas. En la intervención que ellos tuvieron en dicho escenario, recordaron a los distintos actores presentes y a la sociedad en general, que sus padres fueron asesinados en el ejercicio sus derechos políticos luego de firmar un acuerdo de paz muy similar al que se quiere llegar - con el gobierno de Belisario Betancur. Así mismo enunciaron, que como hijos/as de la violencia política guardan los aprendizajes del pasado, por eso exigen su participación en los distintos escenarios de negociación, para con ello visibilizar y reivindicar los ideales de sus padres. A su vez, en su intervención, interpelaron a los distintos actores de la sociedad para que se comprometan con la consecución de la paz, bajo la premisa que: "la experiencia de la vida de nuestros padres sea el mejor argumento para que esta sociedad se comprometa con la paz". (H.I.J.O.S., corpus de la investigación, 16/08/14)

En la última parte se hace una comparación entre el actuar los padres y los hijos/as, allí se afirma que es proclive en el campo de representación política que algunos de los hijos/as se postulen como candidatos para llegar al Congreso de la Republica, con la finalidad de movilizar desde esta instancia un diálogo nacional donde participen las distintas fuerzas activas del país. El diálogo es el principal factor que conecta los ideales de los padres con el de los hijos/as, pues ellos consideran que con él se genera la ampliación de la democracia al incluir las distintas voces que componen el tejido social colombiano. 